\title{
Histórias e memórias de alunos da EJA nas universidades brasileiras e portuguesas após $1974^{1}$
}

Stories and memories of EJA students in brazilian and portuguese universities after 1974

Historias y recuerdos EJA de estudiantes en universidades y portugués brasileña después de 1974

\author{
Albertina Lima de Oliveira \\ Universidade de Coimbra (Portugal) \\ https://orcid.org/0000-0001-9521-528X \\ aolima@fpce.uc.pt \\ Marco Antônio Franco do Amaral \\ Instituto Federal Goiano (Brasil) \\ https://orcid.org/0000-0002-3573-3795 \\ http://lattes.cnpq.br/9694641332419595 \\ marco.amaral@ifgoiano.edu.br
}

\section{RESUMO}

As políticas portuguesas e brasileiras de democratização no ensino vêm proporcionando, ainda que discretamente, um crescimento do número de alunos egressos da Educação de Jovens e Adultos nos cursos de licenciatura das instituições públicas de ensino. Para realizar um mapeamento histórico dos perfis sociodemocráficos dos estudantes egressos da educação de adultos que fizeram licenciatura em Pedagogia no Instituto Federal Goiano, ou Ciências da Educação na Universidade de Coimbra, foi realizado um estudo com a utilização de entrevistas semiestruturadas com ex-alunos desses cursos. Com auxílio das narrativas e suporte metodológico da história oral, foi possível constatar que eles tiveram percursos de escolarização frágeis, maioritariamente trabalham, são casados e estiveram afastados da escola por muitos anos. Alunos brasileiros revelaram que se sentiram motivados a cursar o ensino superior na expectativa de um reenquadramento profissional e, de modo divergente, os alunos portugueses apresentaram forte motivação pela busca de realização pessoal.

Palavras-Chave: Educação de Jovens e Adultos. Instituto Federal Goiano. Universidade de Coimbra.

\footnotetext{
${ }^{1}$ Este trabalho é financiado por fundos nacionais da FCT - Fundação para a Ciência e a Tecnologia no âmbito do projeto UID / HIS / 00460/2019.
} 


\begin{abstract}
The Portuguese and Brazilian policies of democratization in education have led to, albeit discreetly, a growth in the number of students from Youth and Adult Education (EJA) in undergraduate courses of public education institutions. In order to perform a historical mapping of the socio-demographic profiles of adult students who graduated in Pedagogy at the Federal Institute of Goiano (Instituto Federal Goiano), or Educational Sciences at the University of Coimbra, a study was conducted using semi-structured interviews with former students of these courses. With the help of narratives and methodological support of oral history, it was found that they had fragile education pathways, most of them work, are married and have been away from school for many years. Whereas Brazilian students revealed that they felt motivated to attend higher education in the hope of redefining their line of work, Portuguese students, on the other hand, showed strong motivation to pursue personal fulfillment
\end{abstract}

Keywords: Youth and Adult Education. Instituto Federal Goiano. Coimbra University.

\title{
RESUMEN
}

Las políticas portuguesas y brasileñas para la democratización de la educación han proporcionado, aunque de manera discreta, un aumento en el número de estudiantes que se gradúan de la educación de jóvenes y adultos en cursos de pregrado de instituciones educativas públicas. Para realizar un mapeo histórico de los perfiles sociodemográficos de los estudiantes adultos que se graduaron en Pedagogía en el Instituto Federal de Goiano o Ciencias de la Educación en la Universidad de Coimbra, se realizó un estudio utilizando entrevistas semiestructuradas con ex alumnos de estos cursos. Con la ayuda de narraciones y el apoyo metodológico de la historia oral, se descubrió que tenían una escolaridad frágil, principalmente trabajo, están casados y han estado fuera de la escuela durante muchos años. Los estudiantes brasileños revelaron que se sentían motivados para asistir a la educación superior con la expectativa de un replanteamiento profesional y, de manera divergente, los estudiantes portugueses mostraron una fuerte motivación para la realización personal.

Palabras clave: Educación de Jóvenes y Adultos. Instituto Federal Goiano. Universidad de Coimbra. 


\section{Introdução}

As pesquisas brasileiras e portuguesas na área da História da Educação têm revelado que, ao contrário do que ocorria no passado, a história contemporânea tem apresentado políticas de democratização no ensino, principalmente com relação à ampliação da oferta educativa e ao aumento do número de cursos noturnos. Tal fato vem oportunizando, ainda que de maneira contida, o crescimento do número de alunos egressos da Educação de Jovens e Adultos nos cursos de licenciatura das instituições públicas de ensino.

Em Portugal, as políticas de educação e formação têm contribuído para ampliar as trajetórias dos jovens e adultos, como também incentivado a progressão para o ensino superior. Sendo fundamental para as sociedades democráticas a efetiva implementação da educação ao longo da vida, em que as universidades desempenham um papel de relevância, se faz necessário realizar um mapeamento histórico das características sociodemográficas dos estudantes egressos da educação de adultos que cursam licenciatura em instituições públicas brasileiras e portuguesas.

No Brasil, após a promulgação da Lei de Diretrizes e Bases da Educação Nacional (LDBEN) em 1996, houve gradualmente um aumento na oferta do número de vagas nas universidades. Entre a segunda metade da década de 1990 e o ano de 2007, por exemplo, o número de instituições privadas de Ensino Superior teve um aumento de 197,1\%, enquanto o de instituições públicas foi de 18,6\%, segundo dados do Censo da Educação Superior, organizados e divulgados pelo Instituto de Pesquisas Educacionais Anísio Teixeira (INEP). Esse aumento teve um impacto importante no número de alunos matriculados nas Instituições de Ensino Superior, que, ainda segundo o INEP, passou de 1,76 milhão, em 1995, para 4,88 milhões em 2007.

Dados do relatório técnico de 2016 do INEP apresentaram um total de 2.407 Instituições de Educação Superior (IES), com uma "predominância numérica de IES privadas, as quais respondem por $87,7 \%$ do total, seguida da participação das IES estaduais, com $5,1 \%$, IES federais, com 4,4\% e, finalmente, IES municipais, com 2,7\%”. (BRASIL. INEP, 2016). O relatório apresenta também o número de alunos matriculados nos cursos de licenciatura. Em 2016, 7.356 alunos se matricularam na licenciatura. É importante destacar que, entre 2014 e 2016, houve um decréscimo de 6,4\% no número dessas matrículas.

Em Portugal, entre a segunda metade de 1990 e 2018, houve um aumento significativo do número de alunos matriculados no Ensino Superior. Na década de 1990 o número estimado de alunos nesse segmento educacional era de 157.869 e, em 2018, de 372.753 . Segundo a Base de Dados Portugal Contemporâneo (PORDATA), em 2016 se matricularam 13.969 alunos na área de educação e formação intitulada "Educação". Em 2014, o número era de 17.208, ou seja, houve um decréscimo de $18,82 \%$.

Na Educação de Jovens e Adultos (EJA), os dados do INEP apresentam um total de 1.055.347 alunos matriculados no Ensino Médio, segundo o Anexo I do relatório final do censo escolar de 2018. Em 2016, o número total era de 1.004.155. Assim, nesse contexto de democratização no ensino e aumento na oferta educativa de cursos noturnos no Brasil, deu-se um crescimento do número de alunos egressos da Educação de Jovens e Adultos nos cursos de licenciatura das Instituições Públicas de Ensino. Em Portugal, do mesmo modo, as políticas de educação e formação têm contribuído para ampliar as trajetórias dos Jovens e Adultos, como também incentivado a progressão para o ensino superior com medidas direcionadas especificamente para esse público.

A partir dos estudos realizados sobre as Instituições de Ensino Superior e da trajetória da Educação de Jovens e Adultos no Brasil e em Portugal, fazem-se necessários alguns questionamentos: Quais as características dos alunos egressos da Educação de Jovens e Adultos que ingressam no curso de Pedagogia do Instituto Federal Goiano no Brasil e no curso de Ciências da Educação da Universidade de Coimbra em Portugal? Quais elementos históricos e 
familiares podem ter contribuído para a escolha de ingressar na Educação Superior/Ensino Superior? Quais as expectativas futuras para após a realização do curso Superior?

$\mathrm{Na}$ busca de responder a essas questões, o artigo propõe apresentar os dados de entrevistas realizadas com quatro sujeitos de nossa pesquisa que estudaram na educação de jovens e adultos, com o objetivo de conhecer o perfil desses alunos que ingressaram no ensino superior no Brasil e em Portugal nos cursos de Pedagogia e Ciências da Educação. Ao longo deste texto, os sujeitos, todos do sexo feminino, serão denominados de ALUNA A, ALUNA B, ALUNA C e ALUNA D. As duas primeiras são brasileiras e as demais são portuguesas.

Nessa mesma direção, buscaremos também elucidar as trajetórias históricas desses sujeitos que terminaram parte de sua escolarização na EJA e ingressaram na Universidade, superando as dificuldades impostas pela exclusão social e educacional, e elaboraram processos de emancipação social e liberdade (FREIRE, 1987).

\section{Recorte Metodológico}

Foram realizados estudos bibliográficos a respeito do desenvolvimento histórico da Educação de Adultos em Portugal e a sua legislação no pós-Revolução de 25 de abril de 1974 , como também da Educação de Jovens e Adultos no Brasil com a promulgação da Lei de Bases e Diretrizes da Educação em 1996. A partir desse estudo inicial foi desenvolvido um levantamento de leis a respeito do ingresso no ensino superior em Portugal. Em continuação, foi elaborado um levantamento nos cursos de Pedagogia do Instituto Federal Goiano e na Universidade de Coimbra acerca dos alunos egressos da EJA/EFA (Educação e Formação de Adultos, em Portugal) que estão cursando Pedagogia e Ciências da Educação. Foi elaborado um roteiro de entrevista com perguntas relativas à elucidação do problema da pesquisa e na sequência foram entrevistadas duas alunas egressas da Educação de Jovens e Adultos que atualmente fazem o curso de Pedagogia no Instituto Federal Goiano-Go e duas alunas que estudaram na Educação de Adultos em Portugal e ingressaram no curso de Ciências da Educação da Universidade de Coimbra pelo regime especial.

As entrevistas semiestruturadas, tomadas como fonte para a compreensão do passado, foram transcritas e analisadas dentro de uma perspectiva qualitativa, utilizando como metodologia de análise a História Oral Temática. Em consonância com Meihy e Holanda (2007), a história oral é uma metodologia de pesquisa com a realização de entrevistas com protagonistas de acontecimentos no tempo, decorrido ou presente. Assim, essa metodologia não se limita à entrevista ou fonte oral, mas incorpora uma série de ações planejadas a partir de um projeto devidamente elaborado.

De acordo com Alberti (2005), a História oral atua como um método de pesquisa histórica que privilegia a realização de entrevistas com pessoas que participaram de, ou testemunharam acontecimentos, conjunturas, visões de mundo como forma de se aproximar do objeto de estudo. Para Garrido (1993), um dos aspectos mais importantes da utilização de fontes orais é que não apenas se chega a um conhecimento dos fatos pesquisados, mas também à forma como o grupo os vivenciou e percebeu.

Por meio da História Oral, utilizaram-se as memórias de estudantes brasileiras e portuguesas para conhecer as suas histórias e trajetórias. A memória, nesta pesquisa, é percebida como a capacidade de preservar informações e assim nos possibilita recordar e reavivar impressões e compreender o modo como elas foram processadas e representadas de modo individual ou coletivo. (LE GOFF, 1990).

A análise das entrevistas foi utilizada como diretriz para apreender algumas características dos alunos egressos da Educação de Jovens e Adultos que ingressam no curso de Pedagogia do Instituto Federal Goiano e no curso de Ciências da Educação da Universidade de Coimbra em Portugal, os diferentes elementos históricos e familiares que 
cooperaram para as escolhas de ingressar na Educação Superior/Ensino Superior e, por fim, quais as suas expectativas futuras para após a realização do curso Superior.

\section{A trajetória da educação de jovens e adultos no Brasil}

A educação de jovens e adultos, no cenário educacional brasileiro da última década, segundo dados do Censo de 2016 realizado pelo Instituto Brasileiro de Geografia e Estatística (IBGE), vem-se destacando como uma resposta à demanda de mais de 11,8 milhões de pessoas maiores de 15 anos que não sabem ler e escrever, o que equivale a 7,2\% dessa população.

A EJA tem sido tema de políticas públicas com relação ao acesso, à permanência e ao atendimento, principalmente nas últimas décadas, em virtude do avanço da expansão do ensino básico e superior no país. Contudo, apesar das diversas tentativas e iniciativas políticas e sociais de minimizar o problema, ainda há um longo caminho a percorrer para que se possa decisivamente garantir uma educação de qualidade.

O jovem adulto aluno na educação de jovens e adultos no Brasil é essencialmente um trabalhador - às vezes em condição de subemprego ou mesmo desemprego (GADOTTI; ROMÃO, 2007). Nessa dupla jornada entre estudar e trabalhar, a ALUNA A apresenta as suas dificuldades: "Trabalho 35 horas por semana e ainda estudo. Tenho que ir às aulas, não consigo fazer muito mais e faço a minha vida de casa, não tenho empregada, portanto faço de tudo". (ALUNA A, 2019).

A Educação de Jovens e Adultos não se restringe a uma questão relacionada com a idade do educando, mas, acima de tudo, a uma especificidade cultural. Embora se defina um recorte cronológico, os jovens e adultos aos quais se dirige essa ação educativa não são quaisquer jovens e adultos, mas um determinado segmento da população.

O meu sonho entrar lá. Eu fiz somente o ensino médio na EJA. Eu parei porque eu casei e na época não tinha como eu continuar e eu tive que parar. Depois que os meninos cresceram eu voltei para poder terminar e vi que estava fazendo muita falta o estudo, né? Eu trabalhava, mas era como educadora social. Eu fazia projetos e ficava com uma turma de criança ensinando artesanato. (ALUNA A).

Segundo Oliveira (1999), esse educando é também um excluído da escola, porém geralmente incorporado aos cursos supletivos em fases mais adiantadas da escolaridade, com maiores chances, portanto, de concluir o Ensino Fundamental ou mesmo o Ensino Médio.

Conceitualmente, a Educação de Jovens e Adultos no Brasil é uma modalidade específica da Educação Básica que se dedica a atender a um determinado público através de um processo de aprendizagem, formal, informal ou não formal, de modo a possibilitar que esses sujeitos enriqueçam os seus conhecimentos e/ou melhorem sua qualificação profissional e técnica.

Para Di Pierro e Haddad (1999), a Educação de Jovens e Adultos é percebida como

um campo de práticas e reflexão que inevitavelmente transborda os limites da escolarização em sentido estrito. Primeiramente porque abarca processos formativos diversos, onde podem ser incluídas iniciativas visando à qualificação profissional, o desenvolvimento comunitário, a formação política e um sem número de questões culturais pautadas em outros espaços que não o escolar (DI PIERRO; HADDAD, 1999, p. 132).

A conferência Mundial de Educação para Todos, realizada em Jomtien, em 1990, trouxe uma concepção de educação de adultos enormemente divulgada e reafirmada também 
na V Conferência Internacional sobre Educação de Adultos, em 1997, em Hamburgo. Assim, por educação de adultos

entende-se o conjunto de processos de aprendizagem, formais ou não formais, graças aos quais as pessoas cujo entorno social considera adultos desenvolvem suas capacidades, enriquecem seus conhecimentos e melhoram suas competências técnicas ou profissionais ou as reorientam a fim de atender suas próprias necessidades e as da sociedade. A educação de adultos compreende a educação formal e permanente, a educação não formal e toda a gama de oportunidades de educação informal e ocasional existentes em uma sociedade educativa e multicultural, na qual se reconhecem os enfoques teórico e baseados na prática (Art. 3 da Declaração de Hamburgo sobre Educação de Adultos, 1997).

Contudo, tal conceito, caracterizado pela sua amplitude, por diversos momentos, na prática pedagógica, confunde-se com o de ensino noturno. Essa é uma associação equivocada, uma vez que a EJA não se define pelo turno em que é oferecida, mas segundo as características e especificidades dos sujeitos a que ela se destina. Várias iniciativas de educação de adultos em escolas ou outros espaços informais têm demonstrado a necessidade de ofertá-la para além do turno noturno, de modo a permitir a inclusão daqueles que só podem estudar durante o período matutino ou vespertino e comumente trabalham no período noturno.

O inciso VII do Artigo $4^{\mathrm{a}}$ da Lei de Diretrizes e Bases da Educação Nacional (LDBEN) reafirma o dever do Estado de garantir "a oferta de educação escolar regular para jovens e adultos, com características e modalidades adequadas às suas necessidades e disponibilidades, garantindo-se aos que forem trabalhadores as condições de acesso e permanência na escola" (BRASIL, 1996).

\section{História das Políticas de democratização da Educação de Adultos em Portugal}

As (re)formulações educacionais realizadas em nível mundial, a partir da década de 1990 e em continuidade nos anos 2000, assumem como centralidade a formação dos profissionais da educação como possibilidade de desencadeamento de uma reestruturação de seus países.

Historicamente, o Estado Português é marcado por uma forte e duradoura tradição centralizadora. No século XVIII "o Estado toma o lugar da Igreja no controle da educação, através de processos nem sempre pacíficos, e vai-se tornar o mais importante agente de expansão da instituição escolar" (TEODORO; SCOCUGLIA, 2008, p. 20). Após a Revolução de 25 de abril de 1974, emergiu um movimento da comunidade municipal de busca por mais autonomia com maior interferência na política educativa.

Na década seguinte, o Ministério da Educação passou a realizar a inserção das escolas nas comunidades. Em 1984, foi publicado um pacote legislativo que deslocou para os municípios atividades na área da educação. Para Baixinho (2017), essa descentralização incumbiu aos municípios a obrigação de investimento na estrutura das escolas de educação pré-escolar e do ensino básico, os transportes escolares, e a elaboração de materiais para a educação de adultos.

Em 14 de outubro de 1986 foi aprovada a Lei de Bases do Sistema Educativo, Lei n. ${ }^{\circ}$ 46/86, com foco na desconcentração e descentralização da administração pública. Ela estabeleceu o quadro geral do sistema educativo português como "um conjunto de meios pelo qual se concretiza o direito à educação, que se exprime pela garantia de uma permanente acção formativa orientada para favorecer o desenvolvimento global da personalidade, o progresso social e a democratização da sociedade." (PORTUGAL, 1986). Buscava-se 
oportunizar a democratização do ensino com foco na igualdade de oportunidades no acesso, permanência e êxito escolar. Entre outras questões, a Lei propunha que: (1) O Estado não poderia atribuir-se o direito de programar a educação e a cultura segundo quaisquer diretrizes filosóficas, estéticas, políticas, ideológicas ou religiosas; (2) O ensino público não seria confessional; (3) Seria garantido o direito de criação de escolas particulares e cooperativas.

A Lei de Bases do Sistema Educativo português foi fundamental como um prelúdio para o fortalecimento da Educação de Adultos em Portugal. Em seu artigo 12 ela estabelece:

\section{Artigo 12}

(Acesso)

1 - Têm acesso ao ensino superior:

a) Os indivíduos habilitados com um curso secundário, ou equivalente, que, cumulativamente, façam prova de capacidade para a sua frequência; b) Os indivíduos maiores de 25 anos que, não possuindo aquela habilitação, façam prova especialmente adequada de capacidade para a sua frequência.

2 - A prova ou provas de capacidade referidas no número anterior são de âmbito nacional e específicas para cada curso ou grupo de cursos afins.

3 - O acesso a cada curso do ensino superior deve ter em conta as necessidades em quadros qualificados e a elevação do nível educativo, cultural e científico do País, podendo ainda ser condicionado pela necessidade de garantir a qualidade do ensino.

4 - O Estado deve criar as condições que garantam aos cidadãos a possibilidade de frequentar o ensino superior, de forma a impedir os efeitos discriminatórios decorrentes das desigualdades económicas e regionais ou de desvantagens sociais prévias. (PORTUGAL, 1986).

Esse artigo aborda o acesso ao Ensino Superior, com destaque para a aplicação de uma prova especial de ingresso em âmbito nacional voltada para um público com uma idade mínima específica. Ele ressalta também a necessidade de o Estado fomentar ações para garantir aos portugueses o acesso ao Ensino Superior.

$\mathrm{Na}$ década de 1990 e nos anos 2000 ocorreram duas fases importantes. A primeira iniciou-se em 1996 com a reconsideração política do setor educacional em Portugal, a proclamação do ano europeu de aprendizagem ao longo da vida e, ao final de 1999, a reestruturação na Educação de Adultos e a emergência de métodos de europeização das políticas educativas para o setor. A segunda, a partir de 2000, estabelece um novo protagonismo da União Europeia. (BARROS, 2014).

As eleições legislativas nacionais de 1995 deram mais visibilidade à insatisfação de setores mais questionadores e preocupados com a situação da Educação de Adultos como um subsistema público de educação e, consequentemente, destacaram a necessidade de revalorização programática do setor ao assumir como compromisso a importância da educação e formação de todos, numa perspectiva de educação permanente.

Em 1995, o partido socialista chegou ao poder em Portugal e iniciou-se uma nova época política com os XIII e XIV governos constitucionais sob o comando de António Guterres. Ele assumiu o poder em um contexto de déficit educativo implementado pelo Estado Novo, regime que comandou o país no interstício de 1926 e 1974 e acreditava que a educação e a cultura eram um risco para a estabilidade do país. Segundo Benavente (2004), na década seguinte à implantação do Estado Novo houve discussões na Assembleia Nacional que apresentavam posicionamentos adversos à alfabetização questionando a necessidade do aprendizado da leitura. 
A educação portuguesa, na segunda metade da década de 1990, era marcada por um considerável atraso em relação à maioria dos países da Europa Ocidental. Segundo Baixinho (2017), em 1996 dados mostram uma retenção de $12 \%$ no $9 .^{\circ}$ ano de escolaridade, e $24 \%$ no $10 .^{\circ}$. A evasão escolar nesses dois anos era de $10 \%$ e $18 \%$, respectivamente. No $12 .^{\circ}$ a retenção chegava a $33 \%$.

As eleições de 1995 deram a vitória ao partido socialista, mas formou-se um governo sem a maioria no Parlamento em um contexto marcado por: (1) descontentamento da população quanto à educação - $80 \%$ da população portuguesa entre os 15 e 65 anos apresentava níveis precários de leitura, escrita e habilidades básicas da matemática; (2) falta de uma política coesa de Educação de Adultos; (3) evasão e insucesso na escolaridade obrigatória de nove anos; (4) ausência de confiança na escola. (BENAVENTE, 2004).

Segundo Freitas (2010), esse novo ciclo político se estendeu por 7 anos e já teve início em 28 de outubro daquele ano com um compromisso de diálogo e um discurso de proximidade com a educação em uma proposta de centralidade, descentralização e autonomia das escolas.

Em seu programa de governo, António Guterres afirmava que

[...] As políticas educativas, por dizerem respeito a toda a sociedade, implicam a negociação permanente e a participação activa da sociedade e dos cidadãos, o que significa envolver no processo os responsáveis pelos ensinos público, privado e cooperativo, professores, pais, estudantes, funcionários, autarquias e todos os demais protagonistas do processo educativo. As mudanças em educação devem, neste sentido, ser graduais, centradas nas escolas e nas comunidades educativas, sujeitas a avaliação e a um processo constante e participado de ajustamento à realidade. [...] Entender a gestão da educação como uma questão de sociedade, envolvendo todos os parceiros, sem prejuízo da responsabilidade inequívoca do Estado, descentralizando competências na construção de respostas adequadas à diversidade de situações, valorizando a inovação a nível local e a ligação da educação e formação aos seus territórios geográficos e sociais [...]. (PROGRAMA XIII GOVERNO CONSTITUCIONAL,1996, p. 117).

No mesmo programa foram declaradas as diretrizes elementares do relançamento da Educação de Adultos em Portugal com o estatuto de opção estratégica da política educativa do Governo e ênfase em duas medidas: (1) a "negociação de um pacto educativo que assegure a mudança de método, a continuidade de políticas, a concertação e a corresponsabilização de todos os protagonistas do processo educativo" e (2) a que pretendia a "concretização de conselhos locais de educação enquanto órgãos de participação democrática dos diferentes agentes e parceiros sociais, visando a definição de orientações e o acompanhamento das medidas adequadas às diferentes realidades do País" (PROGRAMA DO XIII GOVERNO, 1996, p. 67).

Essa nova fase foi marcada por um reequilíbrio neorreformista para a área da Educação de Adultos, com algumas iniciativas e medidas realizadas em um Pacto Educativo para o Futuro com direcionamento para um novo modelo de percepção do processo decisório na educação de Portugal. "O Pacto Educativo para o futuro foi um instrumento central nesta estratégia, que exigia a participação de todos os parceiros educativos e sociais e, portanto, a pacificação do mundo educativo, o diálogo e a definição de objetivos positivos, valorizando vontades e energias." (BENAVETE, 2004, p. 73).

O Pacto apresentava direcionamentos, objetivos estratégicos e compromissos instantâneos. Ele buscava elaborar uma carta de referência para os diferentes segmentos educativos. Em níveis locais, regionais e central, pretendia fomentar a criação de novos 
órgãos, revalorização dos existentes e melhoria nas condições de trabalho. Seus principais objetivos eram os seguintes:

a) Lançar o desafio para um amplo debate público sobre os problemas da educação e as suas soluções, identificando prioridades e acções concretas;

b) Alargar o conceito de parceiro educativo, identificando um vasto conjunto de interlocutores sociais, o que não deixou de criar resistências junto dos parceiros «tradicionais» (nomeadamente junto das estruturas sindicais de professores).

c) Elaborar os consensos possíveis para a condução das políticas e para a consolidação das respostas concretas não significa unanimidade e ainda menos conformismo; trata-se de um consenso construído sobre as convergências possíveis a partir de diferentes posições, interesses e pontos de vista [...], em termos de 'geometria variável', ou seja, através de partenariados assentes em vantagens recíprocas em domínios concretos, sem que nos enganemos quanto à possibilidade de acordos imaginários sobre todas as matérias.

d) Criar condições para uma certa estabilidade da vida educativa e para a continuidade de processos estruturantes.

e) Valorizar o enquadramento institucional das transformações e da acção educativa concreta, de modo a que a mudança se baseie na transformação sustentada e sustentável das organizações e das práticas.

f) Promover mudanças nas atitudes e nas práticas sociais no sentido da concertação, da co-responsabilidade e da consolidação dos resultados obtidos.

g) Desenvolver estratégias de mudança graduais que privilegiam os mecanismos de acompanhamento, de avaliação e de correcção; o tempo das grandes reformas centralizadas está ultrapassado, e a mudança tem que ter em conta a diversidade de situações e exige o envolvimento de todos os parceiros educativos. (BENAVENTE, 2004, p. 80).

Em 19 de setembro de 1997 o governo publicou a Lei 115, que alterou, entre outros, o Artigo 12 da Lei de Bases do Sistema Educativo português, passando ele a ter a seguinte redação:

1 - Têm acesso ao ensino superior os indivíduos habilitados com o curso do ensino secundário ou equivalente que façam prova de capacidade para a sua frequência.

2 - O Governo define, através de decreto-lei, os regimes de acesso e ingresso no ensino superior, em obediência aos seguintes princípios:

a) Democraticidade, equidade e igualdade de oportunidades;

b) Objectividade dos critérios utilizados para a selecção e seriação dos candidatos;

c) Universalidade de regras para cada um dos subsistemas de ensino superior;

d) Valorização do percurso educativo do candidato no ensino secundário, nas suas componentes de avaliação contínua e provas nacionais, traduzindo a relevância para o acesso ao ensino superior do sistema de certificação nacional do ensino secundário; 
e) Utilização obrigatória da classificação final do ensino secundário no processo de seriação;

f) Coordenação dos estabelecimentos de ensino superior para a realização da avaliação, selecção e seriação por forma a evitar a proliferação de provas a que os candidatos venham a submeter-se;

g) Carácter nacional do processo de candidatura à matrícula e inscrição nos estabelecimentos de ensino superior público, sem prejuízo da realização, em casos devidamente fundamentados, de concursos de natureza local;

h) Realização das operações de candidatura pelos serviços da administração central e regional da educação.

3 - Nos limites definidos pelo número anterior, o processo de avaliação da capacidade para a frequência, bem como o de selecção e seriação dos candidatos ao ingresso em cada curso e estabelecimento de ensino superior é da competência dos estabelecimentos de ensino superior.

4 - O Estado deve progressivamente assegurar a eliminação de restrições quantitativas de carácter global no acesso ao ensino superior (numerus clausus) e criar as condições para que os cursos existentes e a criar correspondam globalmente às necessidades em quadros qualificados, às aspirações individuais e à elevação do nível educativo, cultural e científico do País e para que seja garantida a qualidade do ensino ministrado.

5 - Têm igualmente acesso ao ensino superior os indivíduos maiores de 25 anos que, não estando habilitados com um curso do ensino secundário ou equivalente, e não sendo titulares de um curso do ensino superior, façam prova, especialmente adequada, de capacidade para a sua frequência.

6 - O Estado deve criar as condições que garantam aos cidadãos a possibilidade de frequentar o ensino superior, de forma a impedir os efeitos discriminatórios decorrentes das desigualdades económicas e regionais ou de desvantagens sociais prévias. (PORTUGAL, 1997).

A nova Lei reforça o interesse do governo em criar condições para que as pessoas maiores de 25 anos, que não estejam habilitadas em curso secundário ou equivalente, tenham a possibilidade de ingressar em um curso superior com a realização de uma avaliação que meça a sua capacidade para frequentá-lo.

Em 30 de agosto de 2005, o governo apresenta a nova alteração da Lei de Bases do Sistema Educativo (DL n 49, 2005) com impacto na Educação de Adultos.

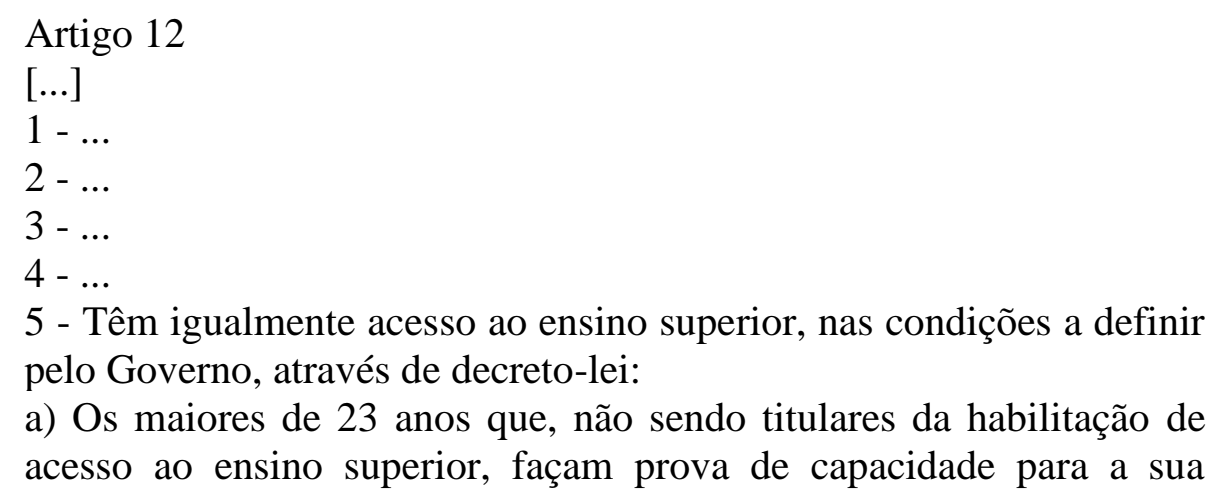


frequência através da realização de provas especialmente adequadas, realizadas pelos estabelecimentos de ensino superior;

b) Os titulares de qualificações pós-secundárias apropriadas.

$6-\ldots$

7 - Os trabalhadores-estudantes terão regimes especiais de acesso e ingresso e de frequência do ensino superior que garantam os objectivos da aprendizagem ao longo da vida e da flexibilidade e mobilidade dos percursos escolares. (PORTUGAL, 2005).

Na Lei n. ${ }^{\circ}$ 49/2005, o Artigo 12 passou a ter nova redação, diminuindo de 25 para 23 anos a idade mínima para a realização das provas de capacidade para ingresso ao Ensino Superior, e também houve a inserção de um parágrafo, flexibilizando, para os trabalhadores estudantes, o ingresso e a frequência. Essa Lei modificou a idade mínima de acesso ao Ensino Superior, baixando-a e inscrevendo-se, assim, numa política de mais flexibilidade na democratização do acesso de estudantes não tradicionais à educação superior/ensino superior. Além disso, no âmbito desta flexibilidade e da reforma do ensino superior português, associada ao Processo de Bolonha (OLIVEIRA, 2012), ela possibilitou também a diminuição da rigidez do sistema educativo ao conferir a cada uma das instituições a responsabilidade pela seleção dos alunos adultos, anteferindo como critério a experiência profissional e formação dos candidatos, de acordo com o Decreto-Lei n. ${ }^{\circ}$ 64/2006, relativo às condições especiais de acesso e ingresso no ensino superior. Desse modo, e em conjunto com o Regulamento Pedagógico da Universidade de Coimbra (Regulamento ${ }^{\mathbf{o}}$ 321/2013, art. 10, "Frequência das aulas"), também contribuiu para a permanência, do aluno que trabalha, no curso de Ciências da Educação. "Como não é exigida a frequência, eu consigo ter mais flexibilidade a estudar e trabalhar". (ALUNA C, 2019).

Nesse contexto de flexibilização, houve maior inserção, nos cursos de licenciatura em Portugal, de alunos maiores de 23 anos que tivessem alguma experiência profissional e formação relevantes e fossem egressos da Educação de Adultos ou que tivessem interrompido os estudos.

Eu comecei a estudar aqui na universidade de Coimbra com 44 anos. Eu fiquei 20 e muitos anos sem estudar. Primeiro porque depois que tirei o 12 eu até concorri para estudar, mas continuava na mesma coisa. As oportunidades eram poucas e na altura não havia bolsas e oportunidades, assim tive que trabalhar, depois trabalhei, construí uma casa, veio uma filha e fui para outro lado. No fundo, para não prejudicar a família. Toda uma série de opções proporcionou esta distância que depois à frente com as novas oportunidades de ingresso eu vim a estudar, pronto. (ALUNA C, 2019).

Em 21 de março de 2006, o presidente Jorge Sampaio publicou o Decreto-Lei n. ${ }^{\circ}$ 64/2006, que regulamentou as provas especialmente destinadas a avaliar a capacidade para a frequência ao ensino superior dos maiores de 23 anos. Ele destaca que "o Programa do XVII Governo Constitucional consagra como um dos objectivos a prosseguir para a política do ensino superior a promoção de igualdade de oportunidades no acesso a este grau de ensino, atraindo novos públicos, numa lógica de aprendizagem ao longo de toda a vida" (PORTUGAL, 2006). Ele reforça ainda que há necessidade de regular a Lei de Bases do Sistema Educativo de modo a adequá-la a um novo modelo com maior extensão no recrutamento de eventuais candidatos e também possibilitar o ingresso a um maior público. Assim, ainda que de modo lento e gradual, houve a ampliação de oportunidades no ingresso. 
"Eu não estudava há quinze anos. Eu parei por circunstâncias da vida. Minha mãe faleceu e, portanto, teve um momento ali... e só mais tarde é que retomei. Meu filho estava agora mais autónomo em nível de escola e deu para conciliar os horários da escola e eu também vir frequentar a licenciatura com as novas oportunidades de ingresso. (ALUNA D, 2009).

Para a ALUNA D, a mudança na legislação também contribuiu para o seu ingresso no curso de Ciências da Educação da Universidade de Coimbra. Ela não estudava há quinze anos e, após um reajuste familiar, conseguiu aliar as novas oportunidades com a mudança da legislação e o seu desejo de fazer o curso de Ciências da Educação.

\section{Alunos da Educação de Jovens e Adultos no curso de Pedagogia do Instituto Federal Goiano - Morrinhos}

A pesquisa, ao analisar algumas características dos alunos oriundos da EJA que estudam no curso de Pedagogia do Instituto Federal Goiano, possibilitou também conhecer as características gerais dos alunos que fazem o curso de Pedagogia em Morrinhos-GO. O curso teve início em 2013 com uma entrada anual de 40 alunos utilizando a nota do Exame Nacional do Ensino Médio (ENEM).

Em linhas gerais, 55\% dos alunos do curso de Pedagogia advieram de escolas públicas da cidade de Morrinhos-Go e 45\% das cidades circunvizinhas a até $70 \mathrm{~km}$ de distância. Possuem uma renda familiar abaixo de três salários mínimos, $40 \%$ exercem algum tipo de atividade remunerada e seus pais e mães possuem baixo índice de escolaridade. "É o primeiro curso. Eu ingressei em 2015. Eu já trabalhava na área da educação como educadora social em um projeto do Banco do Brasil chamado BB comunidade". (ALUNA A, 2019). Eu tive o "incentivo de um irmão que também se formou depois de idade com os filhos e acreditava que todos nós deveríamos ter um ensino, uma educação, ter uma oportunidade de seguir em frente" (ALUNA B, 2019).

Outro ponto de destaque nos achados da pesquisa é o fato de estudar na EJA ser uma ponte para o Ensino Superior em decorrência dos estímulos recebidos dos professores: "Eu fiquei parada 16 anos antes de voltar para a EJA. Eu estudando na EJA tinha uma professora que me incentivava muito e já tinha uma turma que estava estudando lá e eu fiquei sabendo do curso.

As aulas no curso de Pedagogia, que tem duração de quatro anos, são noturnas e a frequência é obrigatória. Com relação à questão de ter havido dificuldades de aprendizagem ao iniciar o curso de Pedagogia por serem advindas da EJA, as discentes disseram que não encontraram dificuldades e que a maturidade alcançada até contribuiu para lidar com os enfrentamentos de um curso superior. Após o retorno aos estudos, afirmaram que as mudanças foram significativas em suas vidas. "Eu entrei e não imaginava jamais que eu iria mudar completamente a minha linha de pensamento. Eu achei que só iria entrar para fazer a vontade de minha irmã, mas realmente o meu pensamento mudou depois disso.” (ALUNA B, 2019).

\section{Alunos maiores de 23 anos admitidos por provas especiais de acesso no curso de Ciência da Educação da Universidade de Coimbra}

O Curso de Ciências da Educação ofertado pela Universidade de Coimbra é ministrado em tempo integral ou parcial, em regime presencial e horário diurno na Faculdade de Psicologia e de Ciências da Educação. Essa faculdade tem origens históricas que remontam aos anos de 1911 e 1912, quando, no âmbito do Curso de Filosofia da Faculdade de Letras e do Curso de Habilitação ao Magistério Primário, começou-se a ensinar pela primeira vez, na Universidade de Coimbra, a Pedagogia e a História da Pedagogia. O curso de Ciências da Educação teve 
início no ano letivo de 1990/1991 com um acesso anual muito variável, embora desde 2016 o número seja constante, com entrada de 70 alunos. De modo geral, os/as estudantes maiores de 23 são egressos de escolas públicas do Distrito de Coimbra que interromperam os estudos durante muitos anos e têm uma média de idade de 40 anos. Dados levantados pela secretaria do curso apresentam quatro alunas que estudam em 2019 no curso de Ciências da Educação e que tiveram o ingresso com provas especiais para maiores de 23 anos.

As aulas são realizadas no período matutino e não são obrigatórias. Apesar disso, as alunas disseram que são frequentes às atividades propostas. "Pela questão da idade, eu gosto muito das aulas. Para mim são muito enriquecedoras. Em uma fase inicial eu coloquei a hipótese de não vir a algumas, mas de facto gosto muito dos professores, do envolvimento que se cria com eles." (ALUNA D).

Para as alunas portuguesas que participaram da pesquisa, a entrada no Ensino Superior é percebida como uma realização pessoal.

Uma valorização pessoal, profissionalmente também pode me trazer algo, estamos sempre a aspirar mais, mais por uma concretização pessoal, uma valorização, o aprender, estava a sentir-me estagnada. Precisava fazer algo novo. Tenho uma menina de 22 anos. Sou casada. Os meus pais têm a $4^{\mathrm{a}}$ classe. Sabem ler e escrever. Tenho mais 5 irmãos, nenhum estudou, tiraram apenas a escolaridade obrigatória para a época. Eu fui a única que tirei o secundário e agora já adulta e estou aqui na universidade com a forma diferenciada de ingresso. Eu gostei do plano de estudos já que tinha tido uma amiga que me disse que gostou muito e pronto. Eu gosto desta área. Iniciei em 2016. (ALUNA C).

As alunas, durante a entrevista, também abordaram o quanto foi exigente a entrada para o ensino superior em decorrência da sua situação de vida, desempenhando múltiplos papéis, de entrarem através do regime especial de ingresso e do grande esforço necessário para avançar no Curso de Ciências da Educação. Elas disseram que não encontraram dificuldades particulares, mas demonstram que houve significativas modificações cotidianas. "Minha rotina teve que mudar, o meu esforço triplicou, quadriplicou, não é, mas estou a conseguir fazer, tenho muita força de vontade. Eu comecei a estudar aqui na universidade com 44 anos. Eu fiquei 20 e muitos anos sem estudar." (ALUNA C).

As expectativas futuras em decorrência do ingresso no Ensino Superior também se modificaram: "Confesso que estou realmente a refletir. Gostaria muito de trabalhar nesta área, diria que o meu objetivo é fazer uma tentativa neste sentido, mas é uma etapa de cada vez." (ALUNA D).

\section{Considerações Finais}

Em Portugal, as políticas educativas implementadas após a Revolução de 25 de abril de 1974 não só têm contribuído para ampliar as trajetórias dos Jovens e Adultos, como também incentivado a progressão para o Ensino Superior. Com auxílio das narrativas, foi possível constatar que, em geral, as alunos oriundos da EJA tiveram percursos de escolarização frágeis, marcados por insucesso escolar, maioritariamente trabalham, são casadas ou divorciadas e estiveram afastadas da escola por muitos anos. As alunas brasileiras revelaram que se sentiram motivadas a cursar o Ensino Superior na expectativa de reenquadramento profissional e, de modo divergente, as alunas portuguesas apresentaram forte motivação pela busca de realização pessoal. 
Em geral, consideraram que o ensino superior aumentou a sua curiosidade intelectual, sentiram-se apoiadas pelos professores e apreciaram suas estratégias educacionais, destacando positivamente o relacionamento interpessoal. As alunas brasileiras revelam nas narrativas que tinham mais dificuldade no cumprimento da carga horária do curso e as portuguesas apreciaram a não obrigatoriedade de presença às aulas, num contexto de maior liberdade, o que lhes permite gerir os seus múltiplos papéis e tarefas.

Além disso, a pesquisa revelou que os estudos históricos apontam um descaso com a EJA no Brasil e demarcam ainda uma dívida republicana com os Jovens e Adultos analfabetos.

\section{Referências}

ALBERTI, Verena. Manual de história oral. $3^{\mathrm{a}}$ ed. Rio de Janeiro: Editora FGV, 2005.

BAIXINHO, António Francisco. Políticas educativas em Portugal: governação, contexto local e hibridismo. Eccos - Revista Científica, [s. 1.], n. 42, p. 105-124, 6 fev. 2017. https://doi.org/10.5585/eccos.n42.3606

BRASIL. Instituto Nacional de Estudos e Pesquisas Educacionais (INEP). Censo da educação superior: 2007- resumo técnico. Brasília: INEP/MEC, 2009.

BRASIL. Lei $\mathrm{n}^{\circ}$ 9.394, de 20 de dezembro de 1996. Estabelece as diretrizes e bases da educação nacional. Lei de Diretrizes e Bases da Educação - LDB. Brasília, DF, 1996. Disponível em: www.planalto.gov.br/ccivil_03/leis/19394.htm. Acesso em: 14 jan. 2019.

BARROS, Rosanna. A conceção e implementação da nova política de educação e formação de adultos em Portugal: sinopse histórica de uma viragem na agenda política nacional. In: ALVES, Natália; RUMMERT, Sonia Maria; MARQUES, Marcelo. Educação e Formação de Jovens e Adultos em Portugal e no Brasil: Políticas, Práticas e Atores. Lisboa: Instituto de Educação da Universidade de Lisboa, 2014. p. 13-30.

BENAVENTE, Ana. O PACTO EDUCATIVO PARA O FUTURO: UM INSTRUMENTO ESTRATÉGICO PARA O DESENVOLVIMENTO EDUCATIVO EM PORTUGAL. Revista Iberoamericana de Educación, [s. L.], n. 34, p. 69-108, 2004.

CONFERÊNCIA INTERNACIONAL SOBRE EDUCAÇÃO DE ADULTOS. Declaração de Hamburgo: agenda para o futuro. Brasília: SESI/UNESCO. 1999.

FREIRE, Paulo. A Pedagogia do oprimido. Rio de Janeiro: Paz e Terra, 1987.

GADOTTI, Moacir; ROMÃO, José E. (orgs.). Educação de Jovens e Adultos teoria, prática e proposta. São Paulo: Cortez. 2007.

GARRIDO, Joan del Alcazar i. As fontes orais na pesquisa histórica: uma contribuição ao debate. Revista Brasileira de História, São Paulo, v. 13, n. 25/26, set 92-ago/93.

GUTERRES, António. Programa do XIII Governo Constitucional. 1996. Disponível em: <https://www.portugal.gov.pt/media/464045/GC13.pdf>. Acesso em: 10 mar. 2018. 
HADDAD, Sérgio; DI PIERRO, Maria Clara. Satisfação das necessidades básicas de aprendizagem de jovens e adultos no Brasil: contribuições para uma avaliação da década da Educação para Todos. São Paulo, 1999. 12 p.

LE GOFF, Jacques. História e memória. Campinas: Editora da Unicamp, 1990.

MEIHY, José Carlos Sebe Bom; HOLANDA, Fabíola. História oral: como fazer, como pensar. São Paulo: Contexto, 2007.

OLIVEIRA, Albertina Lima de. O ensino superior no contexto da reforma de Bolonha. In: BALDIN, Nelma; ALBUQUERQUE, Cristina. Conhecimento e responsabilidade: As (re)configurações do saber, da educação e da ação na contemporaneidade. Brasília: Liberlivro, 2012. p. 73-95.

OLIVEIRA, Martha Kohl de. Jovens e adultos como sujeitos de conhecimento e aprendizagem. Revista Brasileira de Educação, Caxambu, v. 12, p. 59-73, 1999.

PORTUGAL. Lei n $^{\circ}$ 46, de 14 de outubro de 1986. Estabelece o quadro geral do sistema educativo. Lei de Bases do Sistema Educativo. LISBOA, PT, 1986. Disponível em: http://www.cnedu.pt/pt/noticias/cne/1039-lei-de-bases-do-sistema-educativo. Acesso em: 14 jan. 2019.

PORTUGAL. Lei ${ }^{\circ} 115$, de 19 de setembro de 1997. Altera a lei ${ }^{\circ} 46$, de 14 de outubro de 1986. Lei de Bases do Sistema Educativo. LISBOA, PT, 1997. Disponível em: http://www.cnedu.pt/content/noticias/CNE/Lei_de_Bases_97.pdf. Acesso em: 14 jan. 2019.

PORTUGAL. Lei $n^{\circ}$ 49, de 30 de agosto de 2005. Segunda alteração à Lei de Bases do Sistema Educativo e primeira alteração à Lei de Bases do Financiamento do Ensino

Superior. Lei de Bases do Sistema Educativo. LISBOA, PT, 2005. Disponível em: http://www.cnedu.pt/content/noticias/CNE/Lei_de_Bases_2005.pdf. Acesso em: 14 jan. 2019.

PORTUGAL. Lei $\mathrm{n}^{\circ}$ 64, de 21 de março de 2006. Regulamenta as provas especialmente adequadas destinadas a avaliar a capacidade para a frequência do ensino superior dos maiores de 23 anos, previstas no n. 5 do artigo 12..$^{\circ}$ da Lei n. ${ }^{\circ}$ 46/86, de 14 de Outubro. Lei de Bases do Sistema Educativo. LISBOA, PT, 2006. Disponível em: http://www.cnedu.pt/content/noticias/CNE/Lei_de_Bases_2005.pdf. Acesso em: 14 jan. 2019.

TEODORO, Antonio; SCOCUGLIA, Afonso Celso. Tempos e andamentos nas políticas de educação: estudos iberoamericanos. Brasília, DF: Liber Livro, 2008. 